\title{
The Development and Evolution of the Integrated Resource Management Philosophy Within the Ministry of Natural Resources
}

by

\author{
Larry A. Douglas'
}

\section{Introduction}

The purpose of this paper is to trace my view of the development of Integrated Resource Management (IRM) within the Ontario Ministry of Natural Resources (OMNR) to outline how it has evolved; how it remains the same and how it may evolve in the future.

There are many ways to describe Integrated Resource Management. However, in his review of the literature, Mitchell concluded that the normal idea associated with the concept is the sharing and co-ordination of values and inputs of a broad range of agencies, publics and other interests when conceiving, designing and implementing policies, programs and projects. The concept of IRM is not new. Its roots in the United States can be traced to John Welsey Powell, Director of the US Geological Survey in the 1870's and Gifford Pinchot, Chief of the US Forest Service at the turn of the century. The greatest manifestation of the concept is in the Tennessee Valley Authority.

In Canada, roots also can be traced to the turn of the century. Early manifestations included the Federal Commission of Conservation, the Prairie Rehabilitation Act. The Conservation Authorities Act and the Agricultural Rehabilitation and Development Act.

\section{Historical Context}

Until the late 1960's, IRM within the then Department of Lands and Forests could be characterized as:

- taking place primarily at the local level during operations;

- ad hoc and informal;

- dependent upon local staff sharing a common view of what and how resource management activities should be undertaken in an integrated way;

- dependent upon the local manager's conviction that operations would take place in an integrated way; and

- varying significantly from district to district.

During the late 1960's several changes occurred that would significantly alter the Ministry's view of the scope and requirements for IRM. Demands on resources and resulting user conflicts increased. In fewer and fewer cases was it

Director, Planning and Environmental Assessment Branch, Ontario Ministry of Natural Resources possible to direct a particular use to an area that didn't face competing demands. Knowledge about differences in land capability and its importance to resource production increased greatly, and the environmental movement emerged. More of the public was concerned about resource management and the impact that various resource management practices had on the environment. A shift of values was occurring with a larger proportion of the population calling for the development of large wilderness areas and the non-game use of wildlife. At the same time government bureaucracies were being introduced to management science with its emphasis on comprehensive planning and control systems. The Policy, Planning and Budgeting System approach stressed the need to state formally objectives, targets, strategies and thrusts, develop programs to achieve these objectives and to review results. Furthermore, an increasing level of specialization was occurring within traditional resource management disciplines and economists, systems analysts and planners were being added to staff.

\section{Evolution}

By the early 1970's, the Ministry responded to increasing user demands on resources and the need for more comprehensive planning by establishing an organization designed to deal with land use and resource issues at the local level. A three-level organization consisting of main office, eight regions and 49 districts was established in 1972. The major responsibility of main office was policy and program development, target and priority setting and evaluation. Key roles of the regions included co-ordination of resource management activities and planning, setting regional priorities, monitoring results and providing technical assistance to districts. The district was the key component in the delivery of resource management programs being the operational level where the management of natural resources would take place.

Preparation of a Strategic Land Use Program also was begun in April 1972. The main intent was to co-ordinate the various land using programs of the Ministry so that optimum benefits would be derived from the province's natural resources. Planning principles were enunciated for the program and included statements such as: plans are developed to achieve objectives; public participation is an essential part of the planning process and plans must allocate land for effective use in relation to the objectives. 
A great effort was put into developing provincial policies for the various programs during the 70's and provincial policies for forestry, provincial parks, fisheries, mineral aggregates and moose were either approved by Cabinet or in the final stages of approval by 1980 . These policies included statements of objectives from which production targets and to a lesser or greater extent land use requirements could be derived.

However, growing pains also were experienced during the period. Program officers often developed policies without full regard for other programs. This tended to heighten land use conflicts since opportunities for trade-offs were reduced and integration across programs at each organization level was difficult to achieve. In addition there was confusion over the role of various levels and types of planning that were underway and programs tended to give heavy priority to planning in their own program areas and consequently corporate level land use planning programs moved slowly.

Nevertheless by the late 1970's early 1980's important progress had been made in overcoming these problems. As a result of an organizational review in 1978/1980, the roles and responsibilities of various levels in the organization were clarified and the role of the line manager for ensuring integration was strengthened. Direction was given on how integrated policy development was to occur and the connection between corporate land use planning and the more specific planning for each individual resource was clarified. As well, a more integrated budgeting system under the control of the line manager was established.

The completion of Regional Strategic Land Use Plans in 1982 and District Land Use Guidelines in 1983 were major steps in achieving greater integration across the Ministry. The District Land Use Guidelines provide an inventory of the natural resources within the District; describe the general objectives and levels of benefits the Ministry hopes to achieve in the district and outline strategies by which they may be obtained. Broad land use prescriptions are identified for areas of Crown land. These prescriptions and strategies provide guidance and information preparing more specific resource management plans, the third level of the planning system.

One particularly important result of the land use planning process was that it required staff from various programs to work together to develop a common product. During the process more awareness of the needs and problems of various programs and their interrelationships was developed.

With the completion of the land use plans and recognition of the IRM gains resulting from them, attention turned to developing a formal statement of policy on IRM and an assessment of how IRM could be enhanced throughout the Ministry Management System. As a result a corporate statement was issued in 1985 by the Deputy Minister. He pointed out that "IRM is the co-ordination of resource management programs and activities so that long-term benefits are optimized and conflicts between programs are minimized". IRM was described as the main corporate philosophy to be used by MNR staff to achieve Ministry goals, objectives and targets. As well, six principles were identified as follows:

i) All components of the Ministry's Management System must operate using the integrated resource management approach and be assessed continually to improve individual components and linkages between components. ii) The onus is on individual staff to contribute actively to the achievement of all Ministry programs wherever this is possible.

iii) Normally, the multiple use of resources will be OMNR's desired direction since it is the best approach to optimizing benefits and minimizing conflicts. However, in some specific cases, or for certain periods of time a single use can be the best approach to satisfy these two criteria.

iv) Natural and human resources should be blended together so as to yield the optimum combination of benefits.

v) Ministry staff must continually strive to maintain open and effective communications within our Ministry, and with outside agencies, interest groups and the public.

vi) The Ministry must have regard for both the individual and combined consequences of its policies, plans and programs.

Another output of the review on how IRM could be strengthened was a document entitled: "A Framework for Resource Management Planning in MNR." This provided a common set of principles and processes for resource management planning. Examples of principles include: public consultation, the use of inter disciplinary planning teams, the need to recognize the capacity of the resource base to provide benefits in both the short and long term. Other principles were designed to ensure that resource management planning takes place within the general direction provided by land use plans and that its outputs could be easily fed into the Ministry's work planning and budgeting system. Finally the responsibilities for resource management planning were clearly established.

Another factor influencing the development of IRM in OMNR has been the Environmental Assessment Act. This Act administered by the Ministry of the Environment requires that a highly structured and comprehensive planning process be followed. OMNR has made a major effort to develop the Class Environmental Assessment for Timber Management on Crown lands in Ontario. As part of this development a very detailed planning process has been developed that stresses integration of timber and non-timber values. Guidelines for moose, tourism and fisheries have been developed. These guidelines identify a range of possible techniques by which adverse impacts of timber management may be prevented or mitigated and a monitoring program to measure the effectiveness of these guidelines is being developed.

\section{IRM Today}

Over the last 20 years the concept of IRM within OMNR has evolved in a number of ways. IRM has been formally adopted as main corporate philosophy and a clear statement has been made that all staff are expected to seek out ways of applying it. It is now understood that IRM is an important consideration for all components of OMNR's management system - policy, planning, operations and evaluation. All three levels of the organization need to pursue IRM - not just the delivery level, and it is recognized that staff need new skills, such as facilitation, mediation and conflict management as well as better communications skills. Public involvement is now accepted as an essential component of resource management. Staff must now have a greater understanding of the implications of the actions being proposed - not only to meet requirements of the Environmental Assessment Act but also to meet greater public expectations. 
It is clear that a positive attitude to the IRM Philosophy by staff and managers is the main ingredient for success. The greatest opportunity for applying the IRM philosophy will always exist at the local level during resource management planning, work planning and operations.

\section{The Future}

Our concept of IRM will continue to evolve in the future. Monitoring programs will more clearly establish cause-effect relationships. As a result, the need to focus more clearly on the key relationships will become apparent. Many of the popular myths may well be destroyed in the process. Geographical information systems will make it possible to relate various types of resource data on whatever geographical area that is appropriate for the situation under review. It will become increasingly feasible to consider several courses of action to achieve any given objective. This should generally lead to more creative and effective solutions. Planning processes will become simplified and more innovative as we come to know the practical limits of comprehensive planning. Accountability for resource management will increase as resource managers defend their plans and the results of their plans, intended and not intended, to a better educated public and in front of administrative tribunals. 